\title{
Accessibility Futures
}

\author{
Paul Anderson, ${ }^{*}$ David Levinson ${ }^{\dagger}$ and Pavithra Parthasarathi ${ }^{\ddagger}$ \\ * École Polytechnique Fédérale de Lausanne \\ +University of Minnesota \\ ${ }^{\ddagger}$ Hampton Roads Transportation Planning Organization
}

\begin{abstract}
This study uses accessibility as a performance measure to evaluate a matrix of future land use and network scenarios for planning purposes. The concept of accessibility dates to the 1950s, but this type of application to transportation planning is new. Previous research has established the coevolution of transportation and land use, demonstrated the dependence of accessibility on both, and made the case for the use of accessibility measures as a planning tool. This study builds off of these findings by demonstrating the use of accessibility-based performance measures in the Twin Cities Metropolitan Area. This choice of performance measure also allows for transit and highway networks to be compared side-by-side. For roadway modeling, zone-to-zone travel time matrix was computed using stochastic user equilibrium (SUE) assignment with travel time feedback to trip distribution. A database of schedules was used on the transit networks to assign transit routes. This travel time data was joined with the land use data from each scenario to obtain the employment, population, and labor accessibility from each traffic analysis zone (TAZ) within specified time ranges. Tables of person-weighted accessibility were computed for 20 minutes with zone population as the weight for employment accessibility and zone employment as the weight for population and labor accessibility. Maps of accessibility by zone were produced to show the spatial distribution of accessibility across the region. The results show that a scenario where population and employment growth are concentrated in the center of the metropolitan area would produce the highest accessibility no matter which transportation network changes are made. However, another scenario which concentrates population growth in the center of the metropolitan area and shifts employment growth to the periphery consistently outperforms the scenario representing the projected 2030 land use without any growth management strategy.
\end{abstract}

\section{Introduction}

Transportation and land use are inter-dependent. The relationship between these two has been used to explain the growth patterns of cities, and continues to be influential in the decisions by businesses and individuals of where to locate in a city. Understanding this relationship is also important for planning future growth. Land use plans and transportation plans need to be compatible if the goals of both are to be realized (Walton and Shaw 2003).

Accessibility is defined as the ability of people to reach their destinations to meet their needs and satisfy their wants, and has been long used in transportation planning (Hansen 1959). It is a function of both land use and the transportation network and can also be thought of as a measure of the efficiency of a city. This study develops a set of land use and transportation network scenarios, and evaluates accessibility for each scenario. Although the

\footnotetext{
Address for correspondence: Paul Anderson, École Polytechnique Fédérale de Lausanne, Section Génie Civil, GC A2 425 (Bâtiment GC), Station 18, 1015 Lausanne, Switzerland. E-mail: paul.anderson@epfl.ch

Acknowledgments: We would like to thank Shanjiang Zhu and Feng Xie for developing the highway network model and thank Shanjiang Zhu for modifying it to run the congestion pricing scenario. We would also like to thank Andrew Owen for his assistance in developing the transit travel time code. This project was funded by the Minnesota Department of Transportation.
} 
accessibility literature has been around for some time, this sort of application to planning is quite new because computing power and scalability limited the implementation of earlier methods (Lenntorp and Hort 1976, Lenntorp 1978, Harvey 1991, O’Sullivan et al. 2000). The accessibility measures used in this study are also related to research in space-time accessibility, which started with Hägerstrand (1970). Specifically, the use of thresholds with cumulative accessibility is similar to constructing a space-time prism at the originating zone and finding its volume, which is well described in Raubal et al. (2004). Kwan (1998) includes a good overview of the many integral and space-time accessibility measures which are currently in use. Cumulative accessibility is an integral measure which primarily describes places. Kwan (1998) also describes how the accessibility of individuals varies from the accessibility of their place location. We consider the difference in accessibility that results from mode choice (by presenting results for road and transit networks), but disregard the variations between individuals at the same location because the goal of this study is to describe the accessibility of places for the purposes of regional planning.

Transportation planning has traditionally focused on improving mobility and reliability measures of congestion across a metropolitan area. While policy based on these criteria can improve access to jobs or labor, they can have unintended effects as well. First, mobility improvements, when this means improving the connectivity of outlying areas, tend to shape land use by encouraging decentralization (Boarnet and Chalermpong 2001). Second, focusing efforts only on reducing congestion is an automobile-centric policy that ignores and often reduces accessibility for people using other modes. Finally, congestion may not matter much, as Levinson and Marion (2010) show that accessibility increased across the Twin Cities Metropolitan Area from 1995 to 2005 even as traffic congestion worsened by most network measures. This counterintuitive result shows the robustness of accessibility, which can increase in this situation as long as densification outpaces the effects of congestion. Levinson and Marion (2010) have made a strong case for the use of accessibility as a performance measure in land use and transportation planning and we will demonstrate its use here by evaluating a series of future scenarios.

The use of scenarios is widespread in planning practice, a comprehensive review and meta-analysis can be found in Bartholomew and Ewing (2009). Scenarios are not forecasts (though forecasts may be scenarios). In planning, scenarios have often been used in transportation and in land use models to consider alternative policies, and what might their implications be on outcomes like vehicle miles traveled or air pollution. In this study we consider how different land use and network patterns affect accessibility.

One of the network scenarios we consider is a full network implementation of congestion pricing, in which every link is priced. Ours is a link-based approach that charges users for the marginal cost imposed on other travelers by their decision to take a particular link. There are numerous papers which discuss approaches to modeling congestion pricing. Safirova et al. (2007) give an overview of some of the approaches used and compares link-level modeling to network-level modeling of marginal cost. This article concludes that link-level marginal congestion costs are highly correlated with network-level costs and the results suggest that a dynamic full network implementation can produce a "first-best" solution. Zhang et al. (2008) highlight that most transportation economics research focuses on second-best implementation on example networks, while our implementation is first-best (from a spatial perspective), it does not account for queueing and traffic dynamics (which would add considerably to the complexity and run-time of the models), and is on a real metropolitan-level network with complex interactions between prices and alternate routes (which is managed by implementing the pricing within a Stochastic User Equilibrium (SUE) assignment). From a spatial perspective, 
this type of implementation is the ideal pricing system in terms of economic efficiency (Levinson 2010). This article also discusses the issue of equity, which is why many congestion pricing projects have been stalled by political controversy. Levinson (2010) suggests that congestion pricing can be politically acceptable as long as its "losers" are compensated, perhaps by the reinvestment of pricing revenues, but points out that High Occupancy Toll (HOT) lanes are more equitable as they present the user with a choice between priced and free roads. Zhang et al. (2008) approach the same issue from the economic perspective and demonstrate that product differentiation which responds to user heterogeneity produces a higher social benefit. This finding favors HOT lanes, which are a differentiated product, over congestion pricing which offers different prices when alternate routes are considered but offers the same route to all users at a single price. The equity concern explains the more extensive implementation of HOT lanes in the U.S., and is a reason for their inclusion as one of the scenarios in our study.

This analysis is conducted at the transportation analysis zone (TAZ) level. Although data for the existing condition can be found on a more local level like census blocks, the other land uses are scenarios developed under certain assumptions. These could be developed on a block level, but Guo and Wang's (2011) study showed that the smallest level available can exhibit "spurious variation". They concluded that regionalization into homogeneous zones is better for spatial analysis because it can reduce the effect of these local variations, making the more statistically significant variations easier to see.

The next section describes the six land use scenarios, five highway networks, and six transit networks considered in this study. Land use data is developed for each TAZ. A travel time matrix (TAZ-to-TAZ) is developed for each network and joined with land use data to find the total employment, labor, or population reachable for each time threshold. This is followed by the methodology of the accessibility measures used. We then examine a quantitative result: person-weighted accessibility calculated at 30-minute thresholds. The conclusion considers the implications for planning in the Twin Cities and the potential for future research.

\section{Data}

This study analyzes the accessibility of 36 different scenarios, representing each combination of six land use scenarios and six networks. They are as follows.

\subsection{Land Use}

\subsubsection{Land use}

The 2010 land use (scenario $L_{E}$ ) is the existing land use (jobs, households, population by TAZ) in the Twin Cities metropolitan area as of 2010. This is used as a baseline scenario. Maps of population and employment density by TAZ in 2010 are shown in Figure 1 . The highest population densities (over 6,000 per $\mathrm{km}^{2}$ ) are in the neighborhoods just south of downtown Minneapolis. Downtown Saint Paul shows somewhat greater population density compared with the surrounding area. Otherwise, population density ranges from 1,500 to 6,000 persons per $\mathrm{km}^{2}$ across the central cities and inner suburbs. Population density in the remaining suburbs is generally less than 1,500 per $\mathrm{km}^{2}$. Employment in the region is highly concentrated in downtown Minneapolis, with a much smaller concentration in downtown St. Paul. There are significant employment concentrations at many freeway-to-freeway intersections, although most of these employment nodes are on the southwest side of the Metro area. 


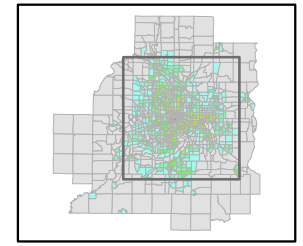

2010 Population Density Residents per Square Kilometer Twin Cities, Minne sota USA
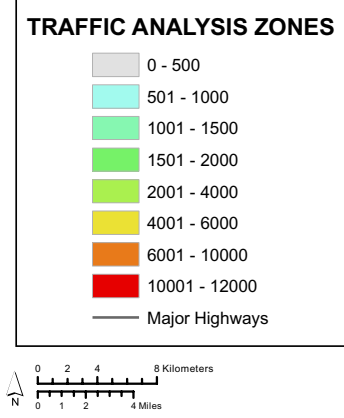

Data Sources

MetCouncil Planning Network

MetCouncil Population File

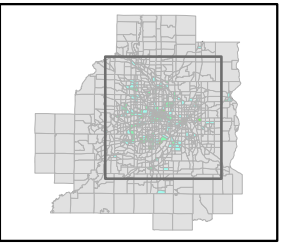

2010 Employment Density Jobs per Square Kilometer Twin Cities, Minne sota USA

\section{TRAFFIC ANALYSIS ZONES}

\begin{tabular}{|l|l|}
\hline & $0-1,000$ \\
\hline & $1,001-2,000$ \\
& $2,001-5,000$ \\
& $5,001-10,000$ \\
& $10,001-20,000$ \\
& $20,001-50,000$ \\
& $50,001-100,000$ \\
\hline & $100,001-200,000$ \\
\hline & Major Highways
\end{tabular}

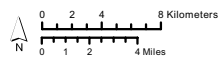

Data Sources

MetCouncil Planning Network MetCouncil Employment File
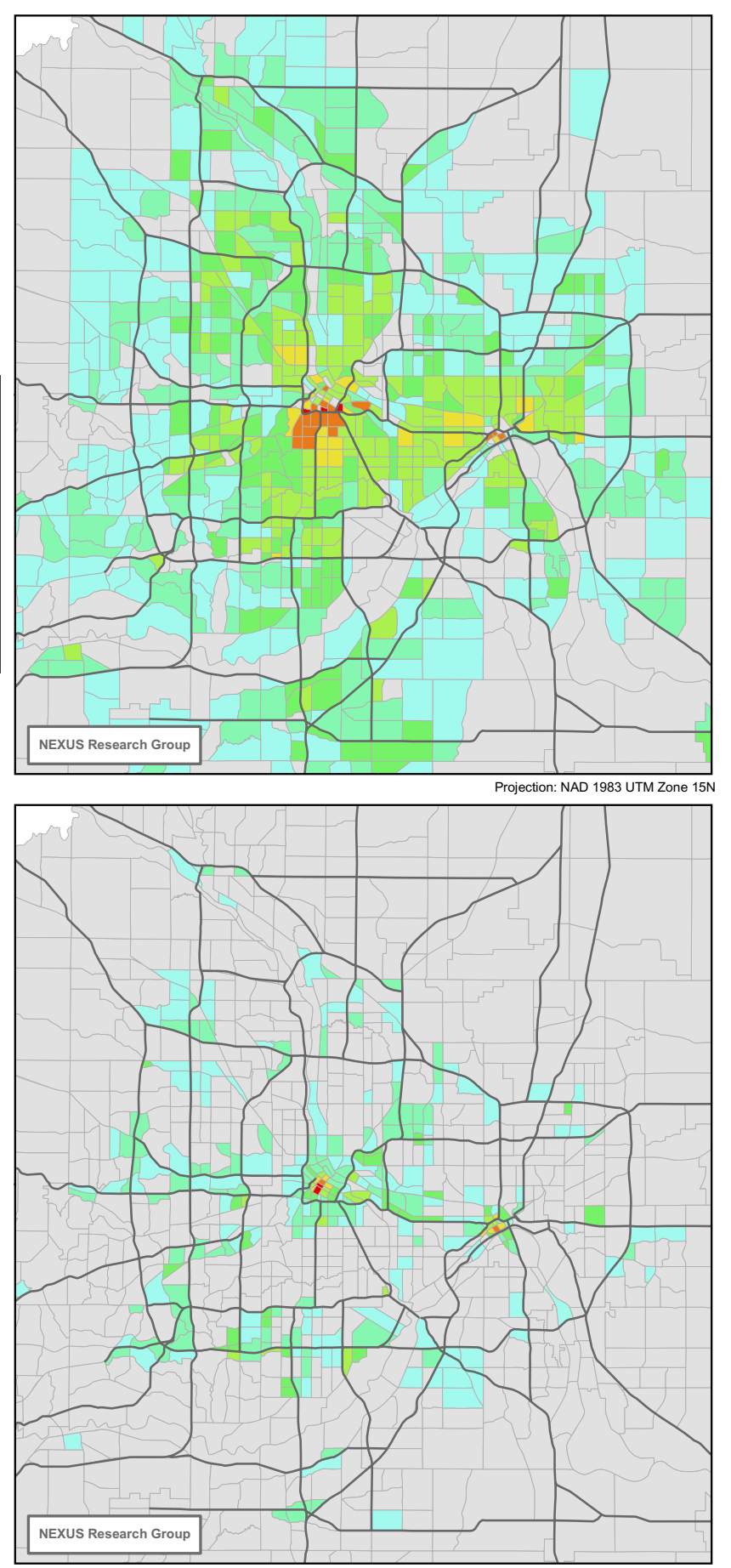

Figure 12010 population and employment density 


\subsubsection{Land use}

The 2030 land use scenario (scenario $L_{F}$ ) is the land use predicted by the Metropolitan Council in its comprehensive plan. The bulk of the growth is expected to occur in outlying areas at low densities. Despite this, there are still some interesting changes. Maps showing the change from 2010 are given in Figure 2. The 2030 employment map is almost the same as the 2010 map in terms of the geographic distribution of employment. Significant increases are projected in downtown Minneapolis and along I-494 on the southwest side of the metro area.

\subsubsection{Centralized population and employment}

The centralized population and employment scenario $\left(L_{C C}\right)$ uses the same metropolitan totals of population, employment and labor as the Metropolitan Council's 2030 Comprehensive Plan, but concentrates all of the growth (beyond 2010) inside the I-494/694 Beltway. All population and employment outside the Beltway is held constant at 2010 values. A map of the centralized population and employment growth can be found in Figure 3. These maps show the increase in population or employment, respectively, from 2010 to 2030, broken down by TAZ. The methodology for land use allocation is discussed in the next section.

\subsubsection{Centralized population, decentralized employment}

The centralized population, decentralized employment case $\left(L_{C D}\right)$ is meant to evaluate the impact on accessibility if population growth occurred only within the I-494/694 Beltway and job growth only occurred outside it.

\subsubsection{Decentralized population, centralized employment}

The decentralized population, centralized employment scenario $\left(L_{D C}\right)$ is the reverse of the previous case. All population growth occurs outside the I-494/694 Beltway and all job growth occurs inside it.

\subsubsection{Decentralized population and employment}

The decentralized population and employment scenario $\left(L_{D D}\right)$ shifts all population and employment growth outside the I-494/694 Beltway. This scenario can be used to evaluate the changes in accessibility that would result from a full dispersion scenario (i.e. no effort is made to increase population/employment in already developed areas). A map of the decentralized population and employment growth is shown in Figure 4.

\subsection{Highway Networks}

\subsubsection{Freeflow}

The freeflow network $\left(N_{0}\right)$ has no congestion whatsoever and is used to evaluate what the accessibility would be under ideal conditions or if there were some technological advance resulting in greatly increased effective capacity (e.g. autonomous vehicles), or some policy that eliminated congestion. 


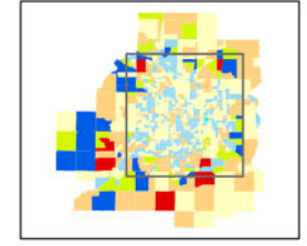

Difference between 2030 and 2010 population forecasts Twin Cities, Minnesota USA 2010 Population Total $=3,043,355$ 2030 Population Total $=3,734,838$ Percentage Change $=\mathbf{2 2 . 7} \%$

TRAFFIC ANALYSIS ZONES
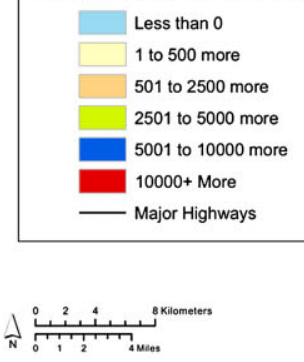

Data Sources

Network

MetCouncil Census File

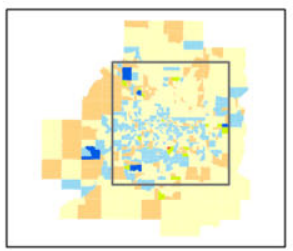

Difference between 2030 and 2010 employment forecasts Twin Cities, Minnesota USA 2010 Employment Total $=1,820,072$ 2030 Employment Total $=2,226,025$ Percentage Change $=\mathbf{2 2 . 3} \%$

TRAFFIC ANALYSIS ZONES
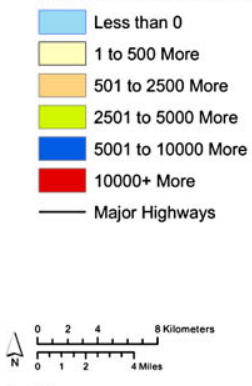

Data Sources

MetCouncil Planning Network

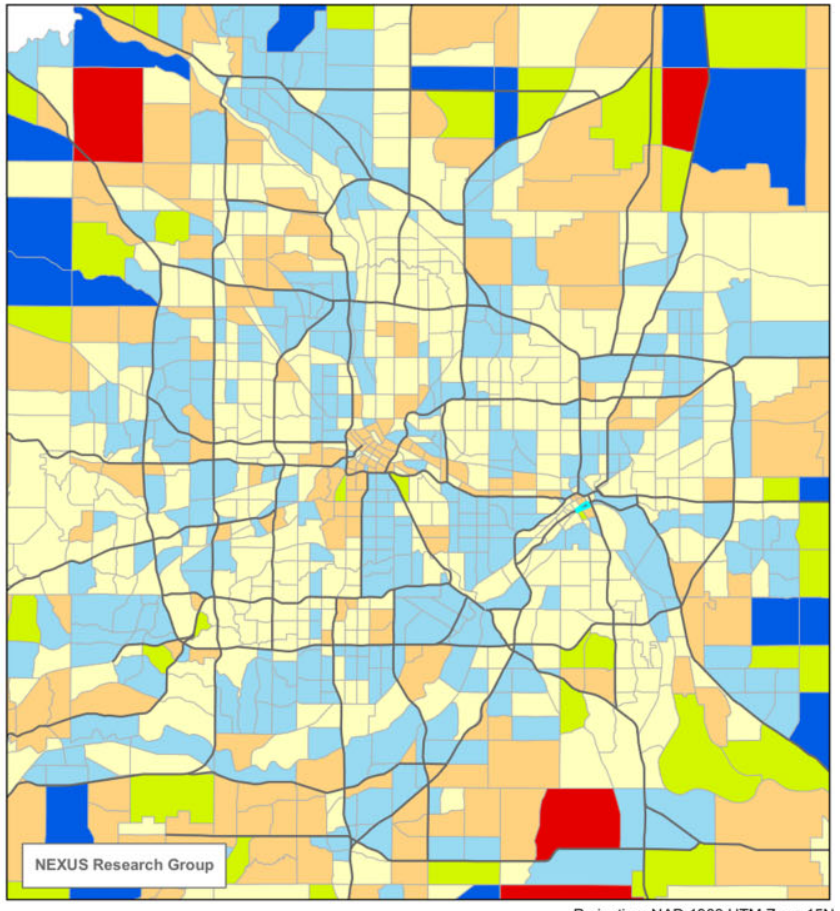

Projection: NAD 1983 UTM Zone 15N

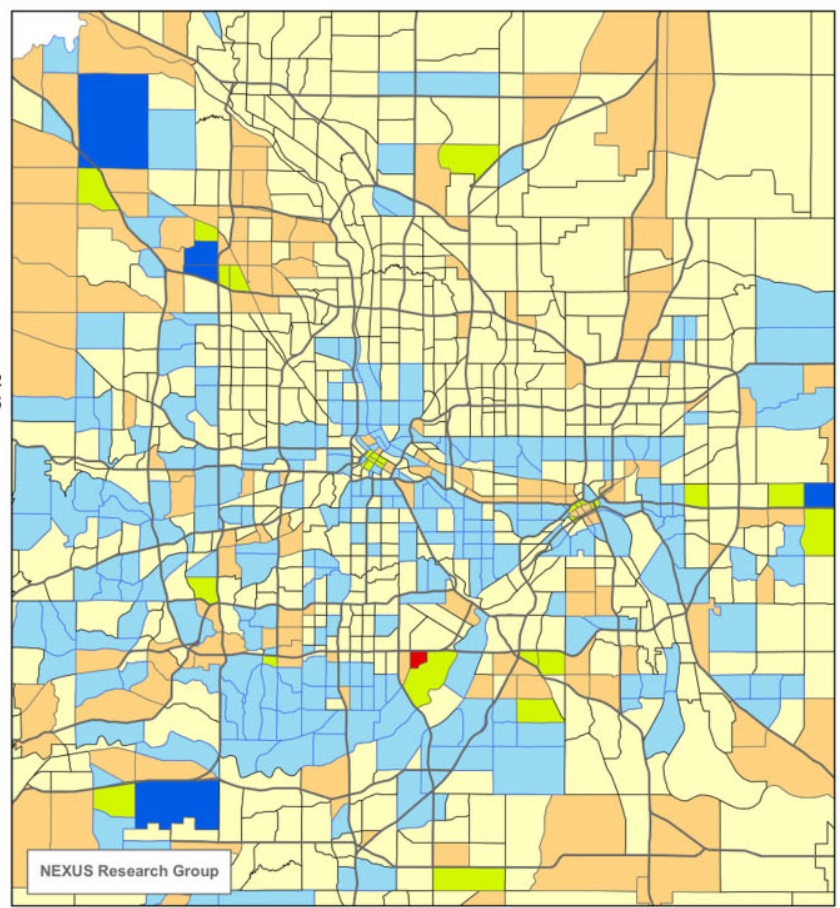

Figure 2 Population and employment change 2010-2030 


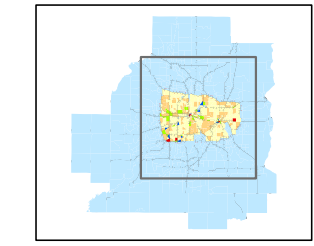

Revised 2030 Population Forecasts Centralized Development

2030 Population Totals $=3,734,838$ Population

Within beltway $=1,999,406$

Outside beltway $=1,735,432$

\section{TRAFFIC ANALYSIS ZONES}

Less than and equal to zero 1 to 500 More 501 to 2,500 More 2,501 to 5,000 More 5,001 to 10,000 More Greater than 10,000 Beltway

Major Highways

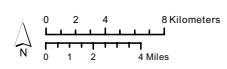

Data Sources

MetCouncil Planning Network

MetCouncil Population File

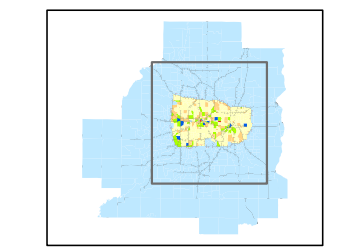

Revised 2030 Employment Forecasts Centralized Development

2030 Employment Totals $=2,226,025$ Employment:

Within beltway $=1,453,335$

Outside beltway $=\mathbf{7 7 2 , 6 9 0}$

TRAFFIC ANALYSIS ZONES

Less than and equal to zero 1 to 500 More 501 to 1,000 More 1,001 to 2,500 More 2,501 to 5,000 More Greater than 5,000 Beltway

Major Highways

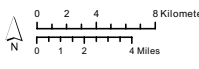

Data Sources

Metwork MetCouncil Population File
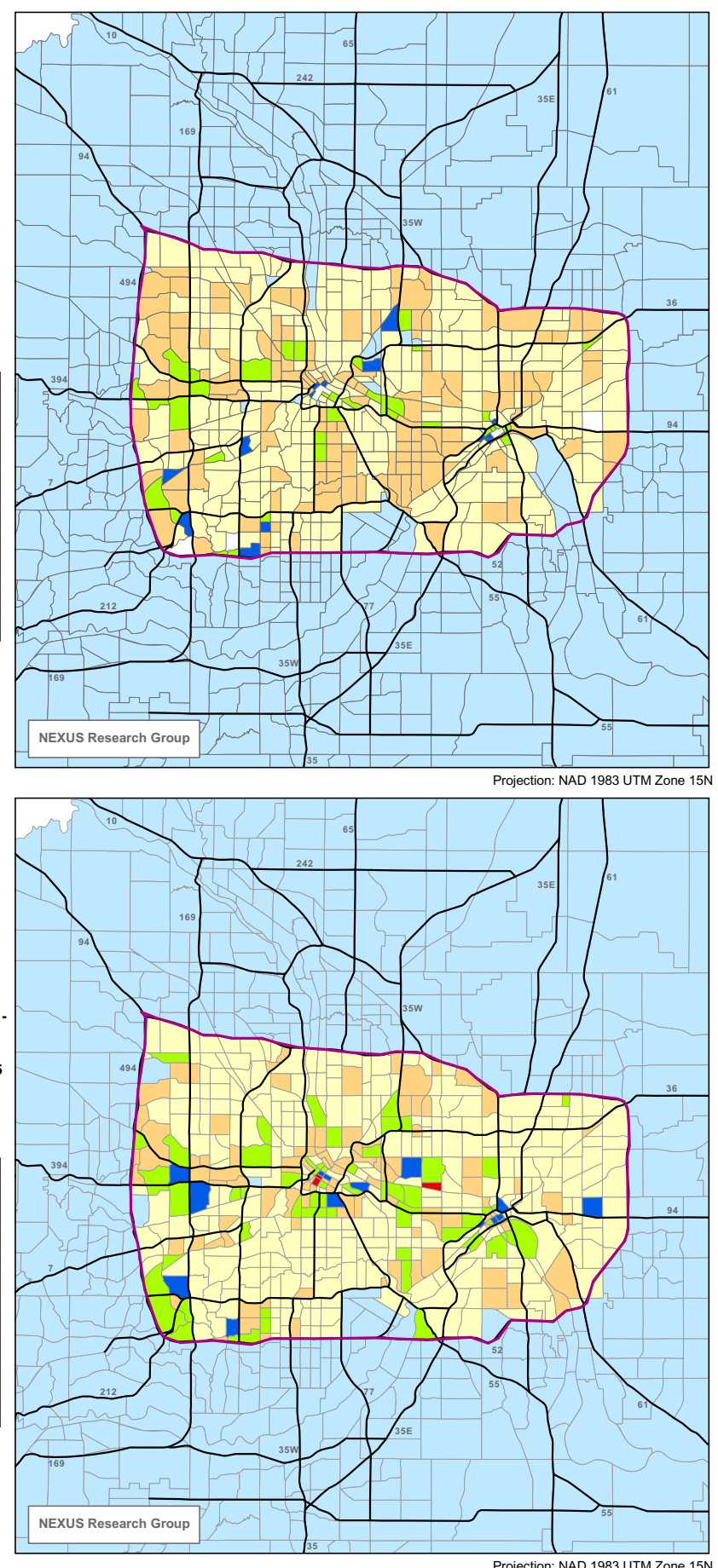

Figure 3 Centralized population and employment growth 


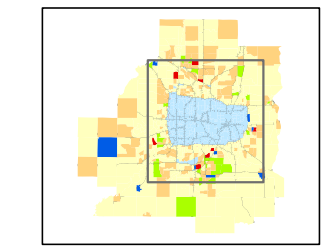

Revised 2030 Population Forecasts Decentralized Development

2030 Population Totals $=\mathbf{3 , 7 3 4 , 8 3 8}$ Population:

Within beltway $=1,249,342$

Outside beltway $=2,485,496$
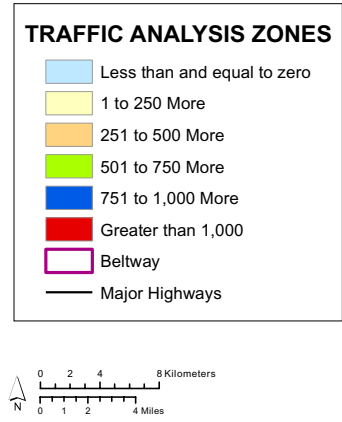

Data Sources

MetCouncil Planning Network

MetCouncil Population File

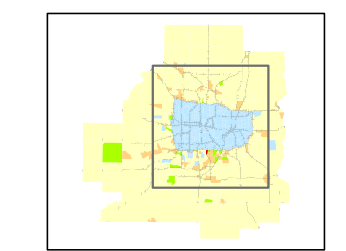

Revised 2030 Employment Forecasts Decentralized Development

2030 Employment Totals $=2,226,025$ Employment:

Within beltway $=997,092$

Outside beltway $=1,228,933$

\section{TRAFFIC ANALYSIS ZONES}

\begin{tabular}{l}
$\square$ Less than and equal to zero \\
1 to 500 More \\
501 to 1,000 More \\
1,001 to 2,000 More \\
2,000 to 3,000 More \\
Greater than 3,000 \\
Beltway \\
\hline Major Highways
\end{tabular}

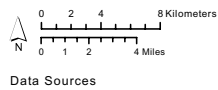

Data Sources

MetCouncil Planning
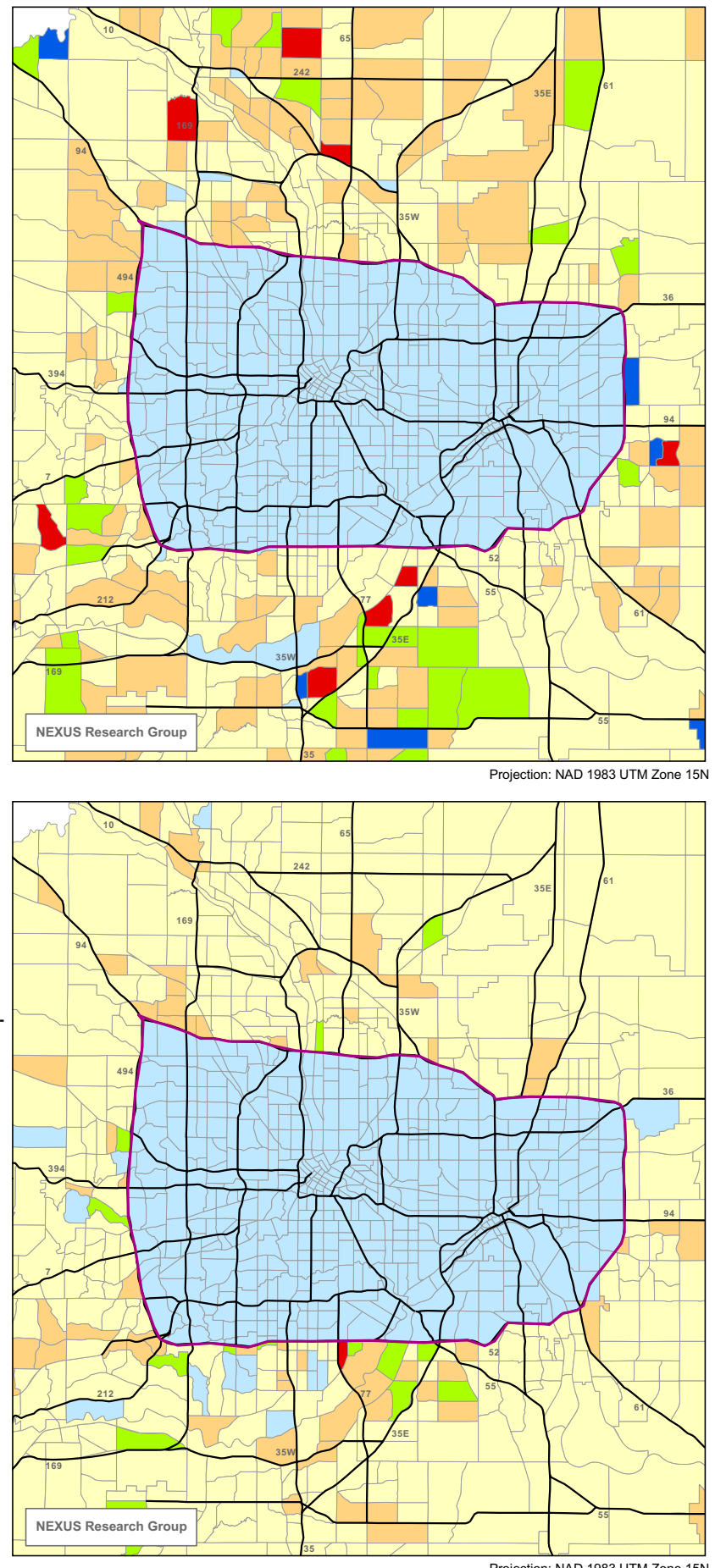

Projection: NAD 1983 UTM Zone 15N

Figure 4 Decentralized population and employment growth 
Effectively, there are only four land use scenarios for this network. The two mixed centralized/decentralized scenarios have the same geographic distribution of accessibility as the appropriate all centralized/decentralized scenario for this network because congestion is absent. In other words, the accessibility to centralized jobs from each zone is the same whether the population is centralized or decentralized. However, the weights for person-weighted accessibility change, so the weighted numbers are different for all six land use scenarios. For all other networks, the location of labor affects access to employment (and vice versa) because it alters congestion patterns.

\subsubsection{Highway network}

This scenario represents the existing highway network as of $2010\left(N_{1}\right)$. The scenario with 2010 Land Use is the existing condition, while all other scenarios with this network show what would happen in 2030 without any network improvements.

\subsubsection{Highway network}

This case $\left(N_{2}\right)$ includes all network improvements envisioned by the Metropolitan Council in their Comprehensive Plan. Most of the changes are new roads or expansions outside the Beltway, but there are a few freeway expansions planned inside the Beltway. A map with these changes highlighted is shown in Figure 5.

\subsubsection{Diamond Lane network}

This scenario $\left(N_{4}\right)$ represents the 2030 highway network with the addition of High Occupancy Toll (HOT) lanes. As of 2010, HOT lanes exist on all of I-394 and on I-35W south of downtown Minneapolis. This network would extend HOT lanes to the remainder of the freeway network on or inside the Beltway. As such, this network will be similar to the freeflow network because freeflow travel is possible on most freeway links (assuming the HOT lanes are regulated to maintain freeflow speed). The cost of tolls is not included in the accessibility measure here.

\subsubsection{Congestion pricing}

This scenario $\left(N_{5}\right)$ represents the 2030 highway network with congestion pricing implemented. This was modeled by assigning users to network paths in order to achieve a system optimal traffic assignment solution. A true system optimal would be difficult to achieve, but this modeled scenario could be implemented by using flow-dependent link tolls to move users away from heavily congested links. The toll that users pay in this scenario was assumed to be in terms of travel time (i.e. link performance function, which is normally the average cost of travel, was converted to the marginal cost function, so the difference represents the additional congestion cost travelers impose on others. This follows the methodology developed and applied by Anderson and Mohring (1997).

\subsection{Transit Networks}

\subsubsection{Transit network}

The $T_{0}$ scenario represents the bus routes, Hiawatha light rail line, and Northstar commuter rail line active in 2010. 


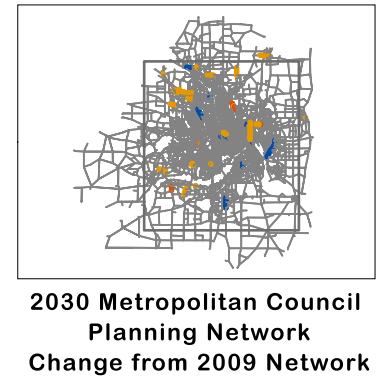

Number of links: 22,823 Numbe of nodes: 8,881

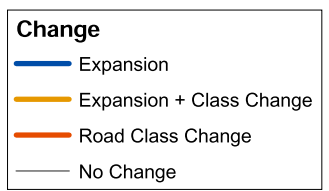

Primary Data Sources: Twin Cities Metropolitan Counci

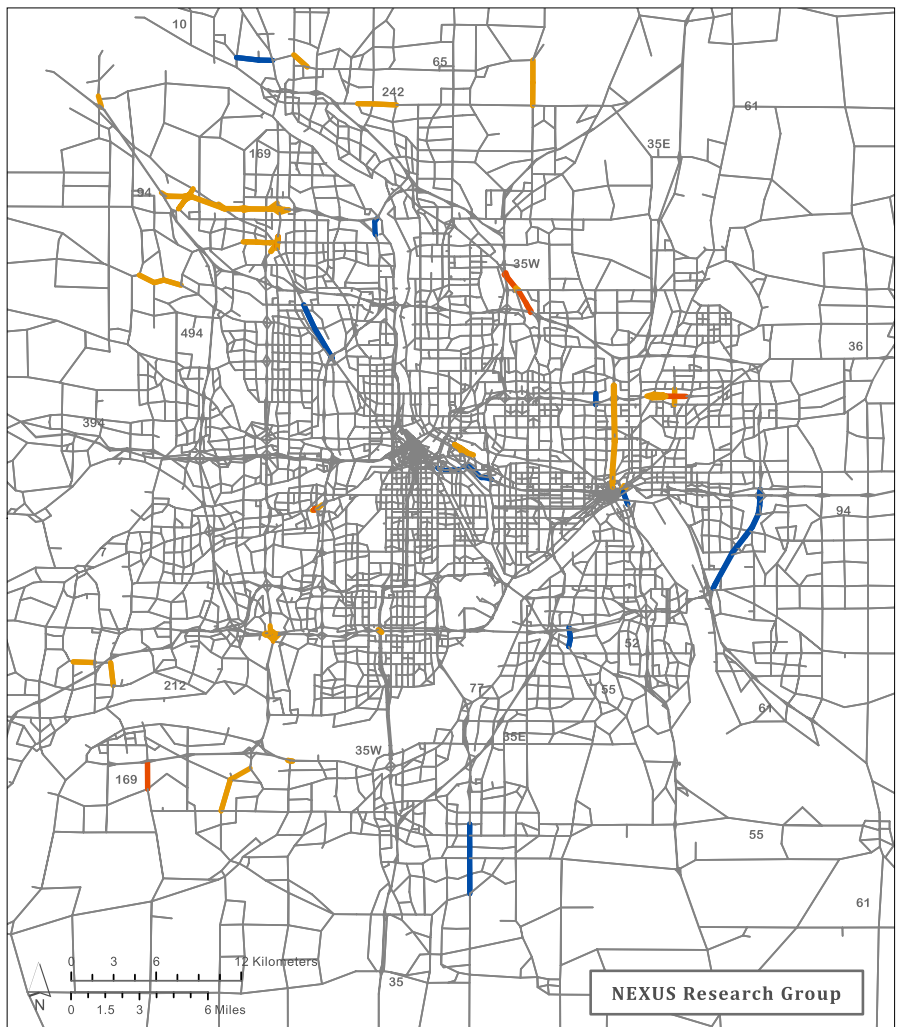

Figure 52030 highway network

\subsubsection{Transit network}

The $T_{1}$ scenario is the anticipated 2030 network according to the Metropolitan Council. It includes the Bottineau, Rush Line, and Cedar Avenue transitways (as Bus Rapid Transit $(B R T))$, the Central Corridor and Southwest light rails, and the portion of the Red Rock commuter rail east of Saint Paul. In addition to these, there are also a number of planned bus routes that are not part of a transitway or feeders into a rail line. In total, this scenario adds $1,736 \mathrm{~km}$ of transit routes. A map of all the transit networks is shown in Figure 6.

\subsubsection{Minneapolis streetcars}

The $T_{2}$ scenario includes the entire $T_{1}$ scenario plus an additional $59 \mathrm{~km}$ of streetcar routes that have been proposed by the city of Minneapolis but have no current schedule for construction.

\subsubsection{Streetcars}

The $T_{3}$ scenario includes the entire $T_{1}$ scenario plus $612 \mathrm{~km}$ of streetcar routes that represent the maximum extent of the historical Twin City Rapid Transit (TCRT) network. This network has near-complete coverage of the region's urbanized area as of 1932. 


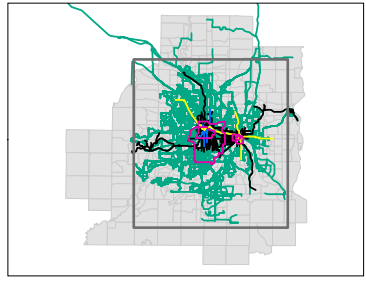

Transit Networks

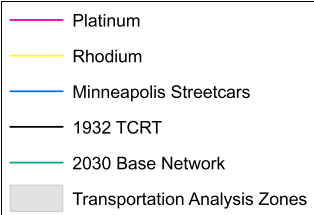

Primary Data Sources:

Twin Cities Metropolitan Council

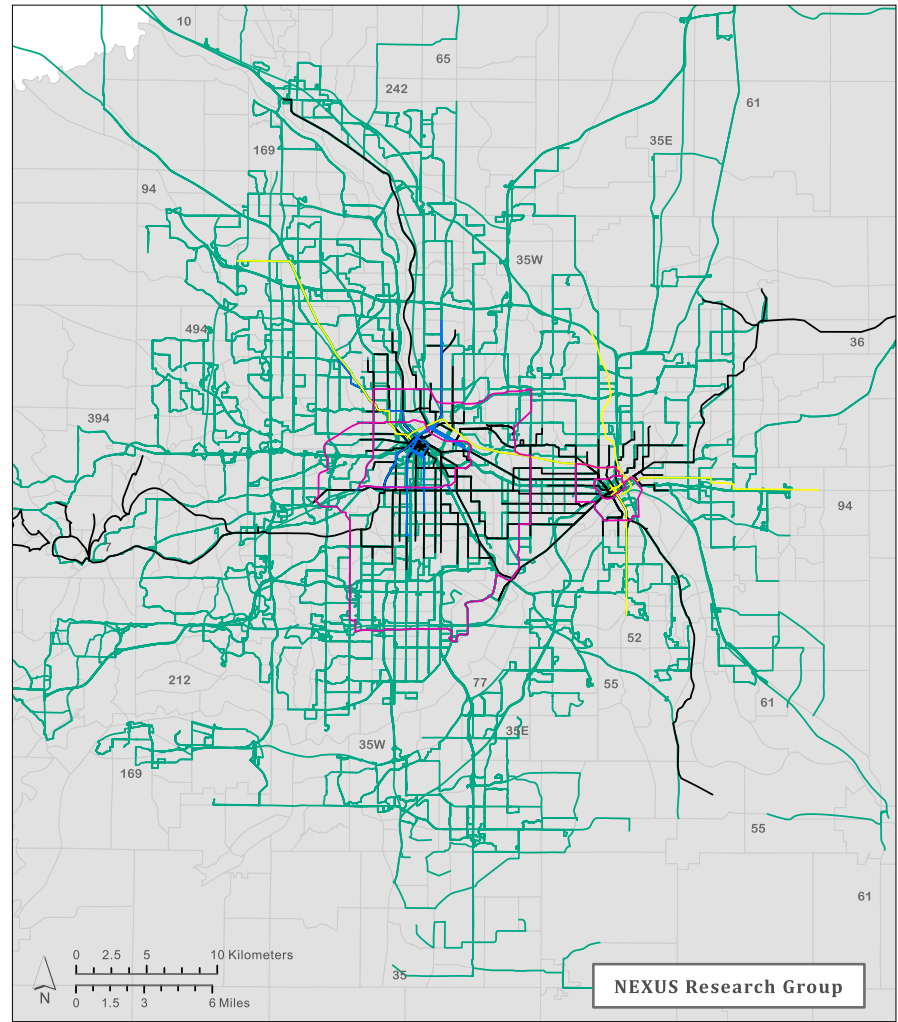

Figure 6 Transit networks

\subsubsection{Rhodium network}

The $T_{4}$ scenario includes the entire $T_{2}$ network plus an additional $78 \mathrm{~km}$ of bus and rail corridors which have been identified by the Metropolitan Council but are not expected to be built by 2030 .

\subsubsection{Platinum network}

The $T_{5}$ scenario includes the Rhodium Network, the 1932 Streetcars, plus an additional $112 \mathrm{~km}$ of circumferential routes designed to connect the region's many radial transit corridors.

\section{Methodology}

\subsection{Alternative Land Use Scenarios}

This allocation procedure is described in Figure 7. Centralized and Decentralized population and employment were allocated based on the 2010 land use and the 2030 Comprehensive Plan forecast. The procedure for centralized population is as follows. 


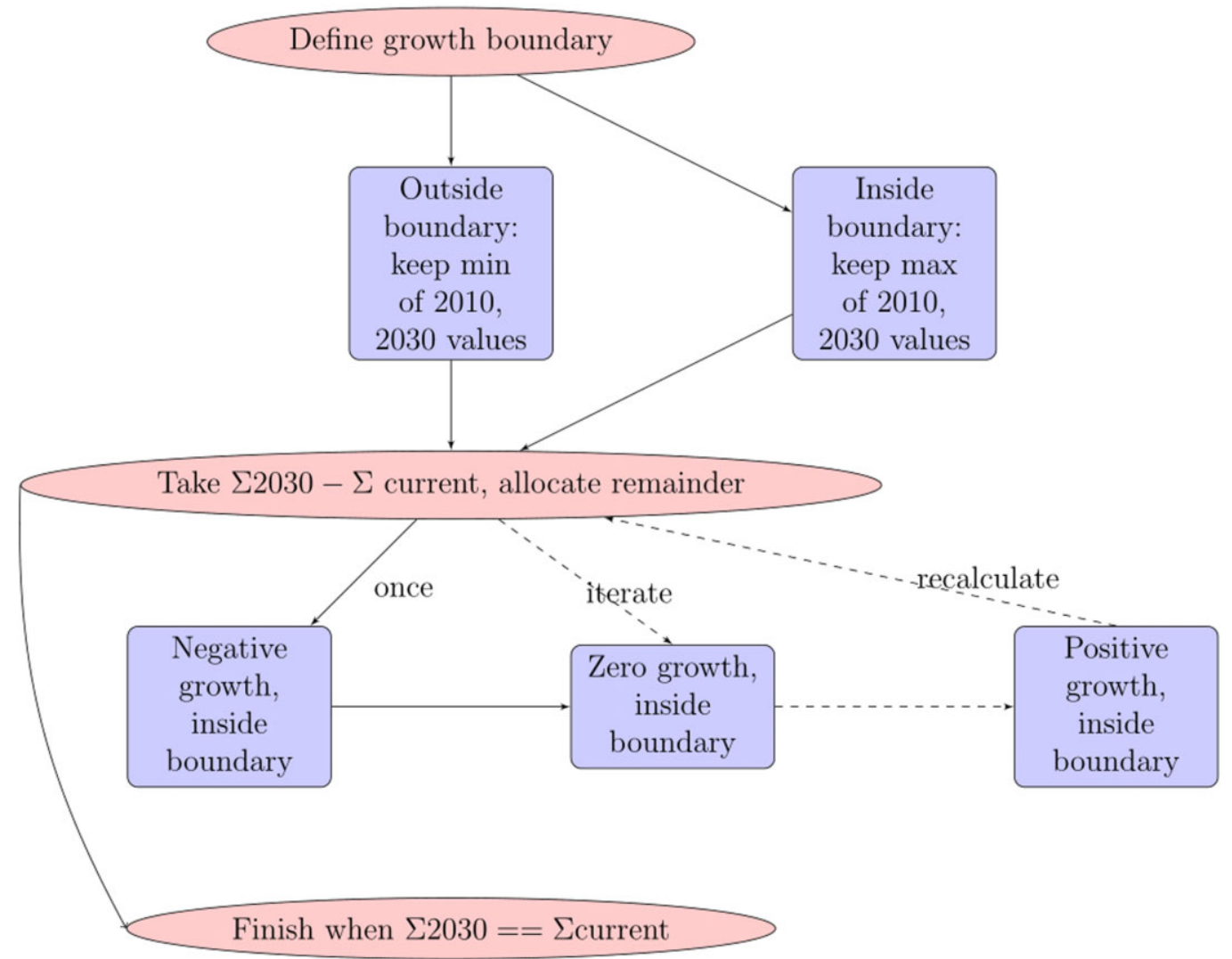

Figure 7 Land use allocation flowchart

As a baseline, zones within the beltline which experienced negative growth from 2010 to 2030 were reverted to 2010 population. Zones within the beltline with zero or positive growth were left at 2030 population. Zones outside the beltline with positive growth were reverted to 2010 population, while zones with negative or zero growth were left at 2030 population.

The first iteration allocated positive growth from outside the beltline to zones with negative growth inside the beltline by the formula:

$$
B_{i+1}=B_{i}+\frac{B_{2010}}{\sum\left(B_{2010}+\bar{B}_{2010}\right)} *\left[\sum \bar{B}_{2030}-\sum \bar{B}_{2010}\right]
$$

where $B=$ TAZs inside the beltline and $\bar{B}=$ TAZs outside the beltline.

The next steps assigned the remaining difference between the total 2030 Comprehensive Plan population and the total population at the end of the last step, first to zones inside the beltline with zero growth, then to zones inside the beltline with positive growth, and then to all zones inside the beltline using the above formula (with the remaining unallocated population replacing the term in brackets). Iterations of this were run until the remaining population 
stabilized. At this point, the remainder was divided evenly among the zones with the 10 lowest (nonzero) populations.

\subsection{Travel Demand Model}

The highway travel demand model used in this project is called SAND: Simulator and Analyst of Network Design. The new 2009 Metropolitan Council planning network that serves as a base network has been conflated to match real network geometry. This network includes 22,477 links, 8,619 nodes, 35 external stations, and 1,236 transportation analysis zones (TAZ) for demand analysis. Links are divided into 15 categories according to their functional classes; link capacities, including AM peak, PM peak and off-peak capacities, are estimated by Metropolitan Council. The travel demand model has been calibrated against the real traffic measured by the loop detectors, and then used to predict the morning peak hour traffic. The model also estimates the morning peak hour factor using the detector data and expands peak hour traffic to Average Annual Daily Traffic (AADT). Given that the public transit ridership only accounts for $3 \%$ of daily travel in the Twin Cities area, SAND directly estimates vehicle trips as a simplification of the traditional four-step process. For the same reason, freight traffic is not explicitly modeled in this study. Instead, we inflate the passenger car traffic to account for the missing freight traffic.

\subsubsection{Calibration}

The travel demand model is calibrated against traffic data provided by loop detector stations. The Minnesota Department of Transportation (MnDOT) maintains about a thousand traffic count stations on freeways throughout the Twin Cities Metro area. Traffic count and speed is measured every 30 seconds and the data are documented on the MnDOT traffic data server. We randomly picked $10 \%$ of the full set of detector stations, removed malfunctioning detectors, and matched 73 out of the remaining stations with the planning network. As shown in Figure 8 , this set of detector stations includes a variety of urban and suburban locations and contains at least one detector pair from all of the major roads that comprise the Twin Cities freeway network. The morning peak hour traffic rate is estimated by averaging the traffic flow from 7:00 to 9:00 a.m. during the weekdays of the first full week in April 2010. The peak hour rate, which is used to expand peak hour cost to daily cost, is estimated by comparing the peak hour rate and daily count observed at these stations.

The target of calibration is to minimize the difference between the morning peak hour traffic flow estimated by the model and the actual morning peak hour traffic count observed on the selected set of links. As trip generation models have been calibrated separately and the peak hour factor has been directly estimated from the traffic data, the only parameter to be adjusted in calibration is the trip distribution friction factor $\theta$. The parameter is calibrated by using a brute force search technique. The friction factor that provides the best fit is $0.151 \cdot \mathrm{min}^{-1}$, resulting in an overall $0.25 \%$ error between the average traffic flows predicted by the model and the average real traffic count given by the detectors. The $R^{2}$, estimated by regressing forecast peak hour traffic flows on observed traffic counts for selected stations, is 0.94 . The root mean square error (RMSE) is $28 \%$. This is less than the $30 \%$ aggregate RMSE recommended by the Montana Department of Transportation (Wegmann and Everett 2008). However, the average error on all links is $0 \%$, so errors are offsetting. Ni et al. (2004) show a similar calibration procedure on a single freeway corridor in Atlanta. 


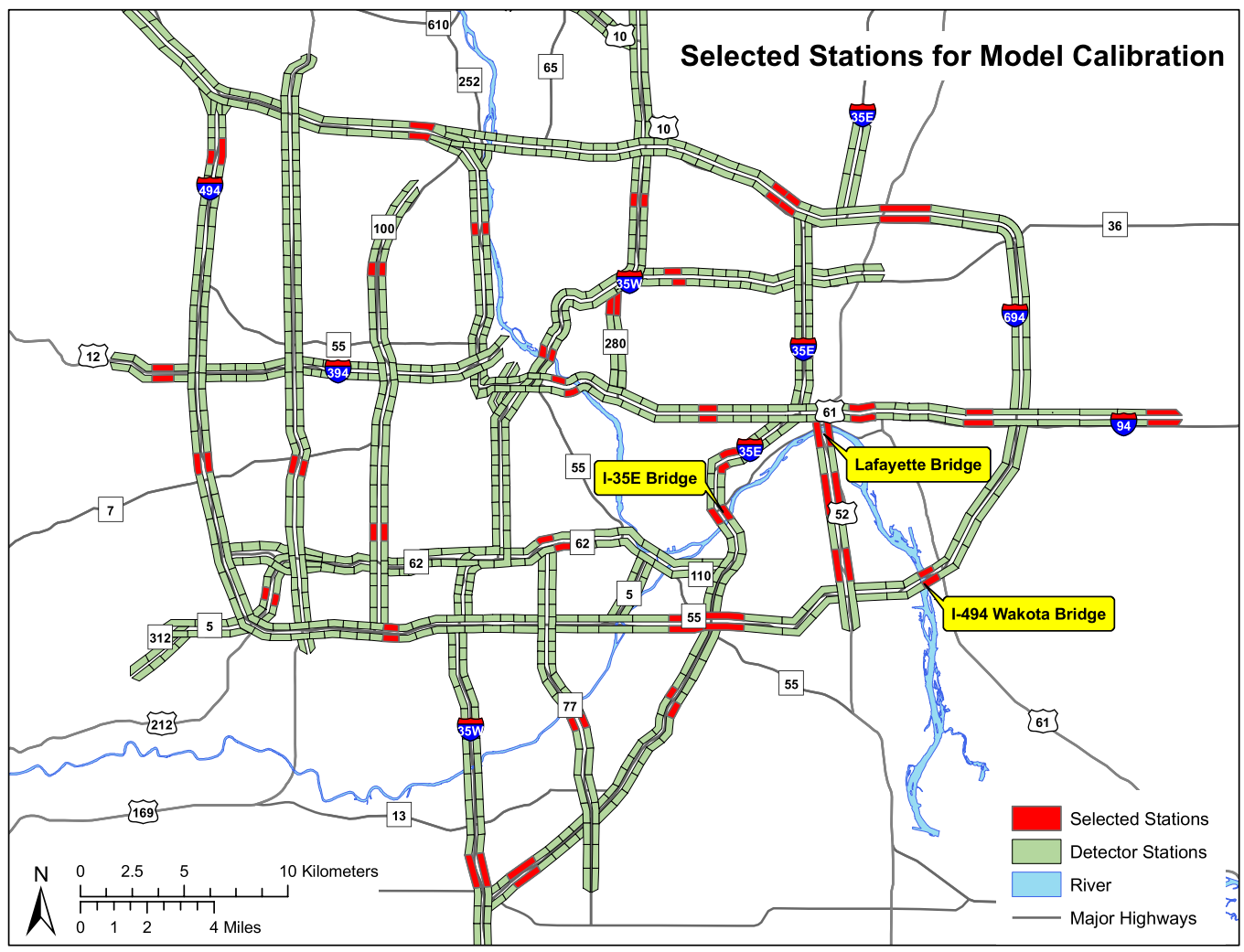

Figure 873 stations selected for model calibration

\subsubsection{Trip generation}

Trip generation estimates the number of personal vehicle trips that originate from (production) or are destined for (attraction) each traffic analysis zone. The traffic production and attraction models are separately estimated by regressing the 2005 composite vehicle trip rates by TAZ, which is provided by Metropolitan Council, on a set of zonal characteristics variables. The model that provided the best goodness-of-fit is adopted. The following explanatory variables turn out to be significantly correlated with the dependent variable:

- Population

- Retail Employment

- Non-retail employment

- Residential density

- Shortest distance from centroid zone to either downtown Minneapolis or St. Paul (estimated within ArcGIS) (Esri 2009)

- Shortest previous distance squared

\subsubsection{Trip distribution}

Trip distribution allocates trips generated in one zone to destination zones in the study area. In our study all trips are treated equally and one aggregate Origin-Destination matrix is gener- 
ated through this process since we do not distinguish trips by purpose. This study adopts a doubly constrained gravity-based trip distribution model. The gravity model assumes that the travel demand between two locations is positively associated with the amount of activity at each location but declines with increasing impedance between them, which is modeled by a negative exponential function of the travel cost here. The friction factor $\theta$ is a parameter to be calibrated in the model. It is an inverse function of travel time, which captures where people prefer longer or shorter trips.

\subsubsection{Route assignment}

Traffic assignment determines the actual route that will be used by travelers between each Origin-Destination pair and the number of vehicle trips that can be expected on each network link. The predicted network traffic pattern depends on the assumption about route choice preferences among travelers. SAND employs a Stochastic User Equilibrium (SUE) model, originally introduced by Daganzo and Sheffi (1977), and assumes that travelers choose the route with minimum perceived travel time. SUE was selected for this study over the alternatives (such as activity-based models and microsimulation) because it is a well-studied and relatively accurate method that can be implemented with fewer inputs (Zhang 2011). As this study deals with future scenarios, all demographic data has to be projected or developed from current values and cannot be measured directly. Attempting to project more demographic values (such as the split of retail/non-retail employment) would introduce more uncertainty. Dial's algorithm (Dial 1971) is used to perform network loading and the Method of Successive Average (MSA) is used to find the SUE link flow. The Bureau of Public Road (BPR) link performance function is adopted to derive the congested link travel time as a function of link flow rate and capacity. Following Leurent (1997), a scaling coefficient of 0.2 is used in the discrete choice module. The convergence for MSA is defined by a maximal allowable link flow change below a threshold of 100 vehicles.

For the congestion pricing network, the link function was transformed from an average cost to a marginal cost:

$$
\begin{gathered}
A C=\frac{L}{v_{f}} *\left(1+0.15 *\left(\frac{Q}{Q_{m}}\right)^{4}\right) \\
M C=\frac{\delta(Q * A C)}{\delta Q}
\end{gathered}
$$

where $M C=$ marginal cost, $A C=$ average cost (the travel time function), $L=$ length, $Q=\operatorname{link}$ flow, $Q_{m}=$ capacity, and $v_{f}=$ freeflow speed.

This increases the costs for congested links by the amount of delay a driver is imposing on other vehicles, thereby moving travelers to less congested links (in the short run) and to changing trip destinations in the long run. These long run feedbacks are included in the model, which iterates between trip distribution and route assignment. This procedure required modifying the model to split the time variable into priced and real components. The priced time was used for route assignments, while the model still needed to return the "real" time for accessibility calculations.

The model returns population and employment accessibility (cumulative opportunities) for each TAZ at the six time thresholds $(10,20,30,40,50,60$ minutes). The freeflow travel 
times were computed by running travel time skims in TransCAD (Caliper Corporation 2008). Additionally, the diamond lane network was created from the 2030 network model run by replacing the link speeds on freeway segments with HOT lanes with freeflow speeds. This assumes high occupancy toll facilities are operating at freeflow speeds.

\subsection{Transit Travel Time Calculations}

The transit scenarios were run using a model developed for this project, following the procedure in Krizek et al. (2007). This code took schedules, transfers, and stop data as inputs. The data for the current (2010) network was supplied by Metro Transit in this format.

New routes were first drawn in ArcMap from the Metropolitan Council's 2030 plan. Stops were added in new areas, but only at a frequency of two per TAZ considering the scale of this analysis. Using Network Analyst tools, nearby stops were associated with each route and the distance between stops along the route was measured. Each new route was classified as an urban local, limited stop, suburban local, express, LRT, or commuter rail and schedule times were calculated based on the average speed (from end to end, which includes stop dwell times) for current routes in the same class. Schedule headways were given by the Metropolitan Council. None of the new routes have timed transfers; for example, if a route has a 15 minute headway then it starts trips at 6:00, 6:15, 6:30 and so on. Transfers between routes were calculated assuming no greater than a $200 \mathrm{~m}$ walk radius.

Once the schedules, transfers, and stops had been produced for the new routes, these data was loaded into the schedule database. For each stop, the code calculates what census blocks can be reached with a maximum of one transfer and saves the lowest travel time to each block. When the code has finished running, a file of block-to-block travel times is exported. The block to block files were converted to TAZ-to-TAZ files and dissolved to obtain the lowest travel time for each TAZ pair. Using ArcMap, another TAZ-to-TAZ matrix was created of walk times, assuming an average speed of $5 \mathrm{~km} / \mathrm{h}$. The walk time matrix takes the centroid to centroid distance between TAZs, multiplied by 1.2, a typical circuity value found by Parthasarathi (2011). These two TAZ-to-TAZ matrices were compared, and the lowest time was taken for each pair. This leads to a low level of accessibility in outlying areas which have no transit service (instead of zero accessibility), as individuals could walk between zones.

\subsection{Accessibility Calculation}

The cumulative opportunity accessibility measure is traditionally defined as:

$$
A_{i, T}=\sum_{j=1}^{J} O_{j} D\left(C_{i j}\right)
$$

where $A_{i, T}=$ cumulative opportunities from a zone $(i)$ to the considered type of opportunities (j) reachable in time $T, \mathrm{O}_{j}=$ opportunities of the considered type in zone $j$ (e.g., employment, shopping, etc.), $C_{i j}=$ generalized (or real) time or cost from $i$ to $j$, and $D\left(C_{i j}\right)=1$ if $C_{i j}<T$ and 0 otherwise.

The threshold $\mathrm{T}$, indicating the time for which we will compute the number of activities that can be reached, varies from 10 to 60 minutes.

The cumulative opportunity measures are combined to develop a complete time-weighted accessibility measure in this article with a different impedance function, defined in Levinson 
and Kumar (1994) as:

$$
A_{i, t w}=\sum_{T=10}^{60}\left(A_{i, T}-A_{i, T-10}\right) \cdot e^{\beta * T}
$$

where $\beta=-0.08$ and $T=$ time threshold for cumulative accessibility.

This measure weighs the cumulative accessibility at 10-minute intervals from 10 to 60 minutes. The result is a zonal population weighted employment accessibility for each TAZ.

An overall person-weighted accessibility $A_{p w}$ is calculated for employment by multiplying the cumulative accessibility by zone at the time threshold by a weight $W_{i}$ (e.g. the zone population) and dividing the product by the sum of the weights. The same calculation was performed for population and labor, but with zone employment as the weight.

$$
A_{p w, T}=\frac{\sum_{i=1}^{I} A_{i, T} \cdot W_{i}}{\sum_{i=1}^{I} W_{i}}
$$

Similarly a composite time-weighted, person-weighted accessibility is:

$$
A_{p w, t w}=\frac{\sum_{i=1}^{I} A_{i} \cdot W_{i}}{\sum_{i=1}^{I} W_{i}}
$$

Cumulative accessibility is one of many measures available and was chosen for this analysis for the ease with which it can be calculated from the available data. It meets criteria for a good accessibility measure, defined by Geurs and Van Wee (2004) as sensitivity to service level changes in the selected transport mode, change in the number of opportunities in a particular place, change in demand for an opportunity in an area with capacity restrictions, as well as insensitivity to changes in opportunities in an unreachable area (within a certain time or using a particular mode). This application, cumulative accessibility with time thresholds, is similar to Bertolini et al. (2005). The person-weighted aggregate measure is a benefit measure according to the classification of Miller (1999), and measures the accessibility benefit accruing to an average individual in each scenario.

\subsection{Diamond Lane Vehicle Hours Traveled}

The vehicle hours traveled (VHT) on the diamond lane network, which is shown in Table 1, assumes that $20 \%$ of users on the affected freeway links get the benefit of the HOT lane, while the travel time for the remaining $80 \%$ is recalculated according to the BPR link performance function. The $20 \%$ figure is an approximation of the HOT/mainline split. According to Swisher et al. (2002), the critical operating threshold for a single HOT lane is 1,300 vehicles/ hour (ensuring a very low probability of congestion and resulting speed drops). An often-used value for the capacity of a general-purpose freeway lane is 2,000 vehicles/hour. If we consider 
Table 1 Scenario benefits

\begin{tabular}{llllll}
\hline Scenario & Land Use & VKT & VHT & VKT/VHT & PWA \\
\hline 2010 Existing & 2010 & $7,555,339$ & 130,232 & 58.01 & 608,431 \\
2010 Network & 2030 Base & $9,467,449$ & 227,229 & 41.66 & 622,123 \\
2030 Network & 2030 Base & $9,883,951$ & 230,038 & 42.97 & 628,570 \\
Diamond Lanes & 2030 Base & $9,883,951$ & $173,076^{*}$ & 57.11 & 777,929 \\
Congestion Pricing & 2030 Base & $9,822,811$ & $195,967^{* *}$ & 50.12 & 762,157 \\
Freeflow & 2030 Base & $9,883,951$ & 136,336 & 72.50 & 836,003 \\
\hline
\end{tabular}

* Does not include tolls

** Includes travel time "tolls"

one HOT/2 mainline and one HOT/3 mainline lanes all operating at capacity, the HOT/ mainline splits would be 24.5 and $17.8 \%$, respectively.

\section{Results}

Figure 9 shows person-weighted accessibility at 20 minutes to employment. Looking across the different land use patterns, the highest person-weighed accessibility to employment in all scenarios comes with centralized employment and population $\left(L_{C C}\right)$. The second highest is usually with centralized population and decentralized employment $\left(L_{C D}\right)$. The 2030 base land use $\left(L_{F}\right)$ comes in third on the existing and 2030 base highway networks, while decentralized population with centralized employment $\left(L_{D C}\right)$ is third in the remaining highway scenarios and in all transit scenarios. In all cases $L_{C C}$ has higher accessibility than fully decentralized growth $\left(L_{D D}\right)$.

In general, centralizing population and decentralizing $\left(L_{C D}\right)$ employment produces more access to jobs than decentralizing population and centralizing employment $\left(L_{D C}\right)$, consistent with the suggestion of (Levinson 1998). This scenario will also produce shorter commute times through the development of "edge cities", employment and retail nodes on the periphery that are surrounded by residential areas.

Compared to the forecast scenario, $L_{C C}$ produces about 20 to $25 \%$ more accessibility, depending on the network configuration.

Figure 10 shows the time-weighted accessibility measure. Although the numerical values are different, the overall trends are essentially the same. Centralized population and employment produces the highest accessibility, followed by centralized population and decentralized employment. The decentralized population, centralized employment scenario performs better than the 2030 comprehensive plan on the freeflow, diamond lane, and 2030 transit networks, but falls behind on the 2010, 2030, and congestion pricing networks. The fully decentralized scenario is third best on all transit networks using the time-weighted measure, but it has the worst accessibility at a 20 minute threshold (Figure 9). This suggests that the decentralized development pattern does produce access to transit (at suburban centers which are served by the express bus network), but at the same time trip lengths are increasing so performance at the 20 minute threshold is poor.

Table 1 shows a comparison of traditional highway performance measures with 20-minute person-weighted accessibility for the 2030 base land use scenario. The current situation (2010 


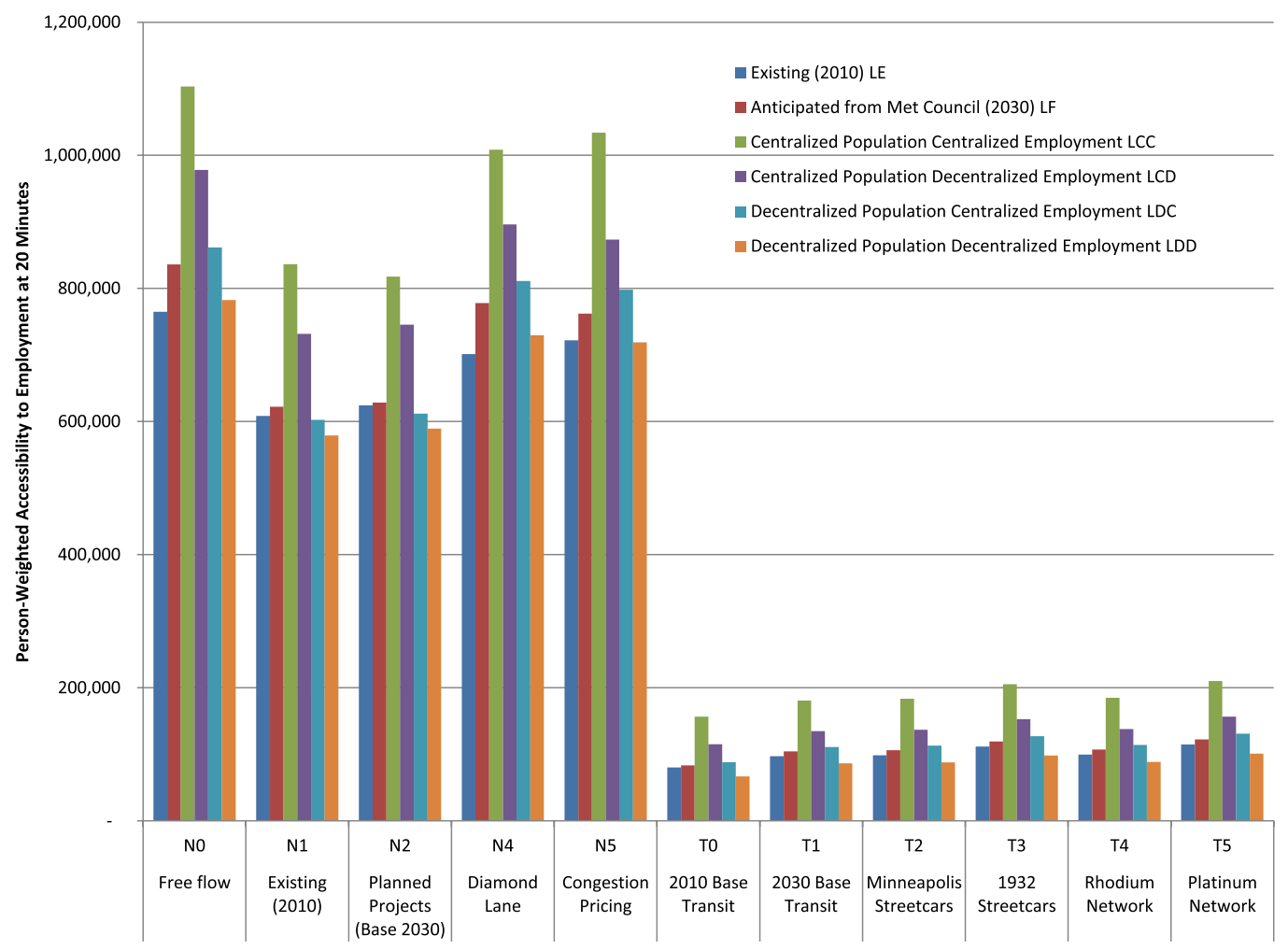

Figure 9 Person-weighted accessibility to jobs: 20 minutes

network with 2010 land use) is also provided as a reference. This shows that highway congestion is predicted to increase in nearly all network scenarios, with freeflow as the one exception where the vehicle kilometers traveled (VKT) divided by the vehicle hours traveled (VHT) increases. (This is essentially the average speed of travel on the network.) As a note, the 2030 network, diamond lane, and freeflow scenarios have the same VKT because the latter two are constructed from the former by setting the speed on affected links equal to the freeflow speed.

We can also observe in this table that the congestion pricing scenario causes a $0.6 \%$ decrease in VKT compared to the 2030 network, but a $14.8 \%$ reduction in VHT. Congestion is decreased, as demonstrated by the large drop in VHT, but some users take longer alternate routes to avoid higher tolls on congested links, which leads to the much smaller change in VKT.

Comparing networks, the freeflow network $\left(N_{0}\right)$ has the highest accessibility, followed by the Diamond Lane network $\left(N_{4}\right)$ (which has freeflow times on the freeway system inside the Beltway) (excluding the cost of tolls). The freeflow network $\left(N_{0}\right)$ has about $20 \%$ more accessibility than the forecast network $\left(N_{2}\right)$. So if some technology could bring about freeflow travel, we would expect accessibility to be about $20 \%$ higher in peak flow periods. It is even greater for shorter time thresholds (i.e. the number of jobs that can be reached in 20 minutes increases more than 20\%). The Diamond Lane and Congestion Pricing scenarios are relatively similar and have about two-thirds as much gain as $N_{0}$ compared to $N_{2}$.

The anticipated 2030 network $\left(N_{2}\right)$ generally bests the existing 2010 network $\left(N_{1}\right)$ except when there is centralized population and centralized employment $\left(L_{C C}\right)$, but the two are very 


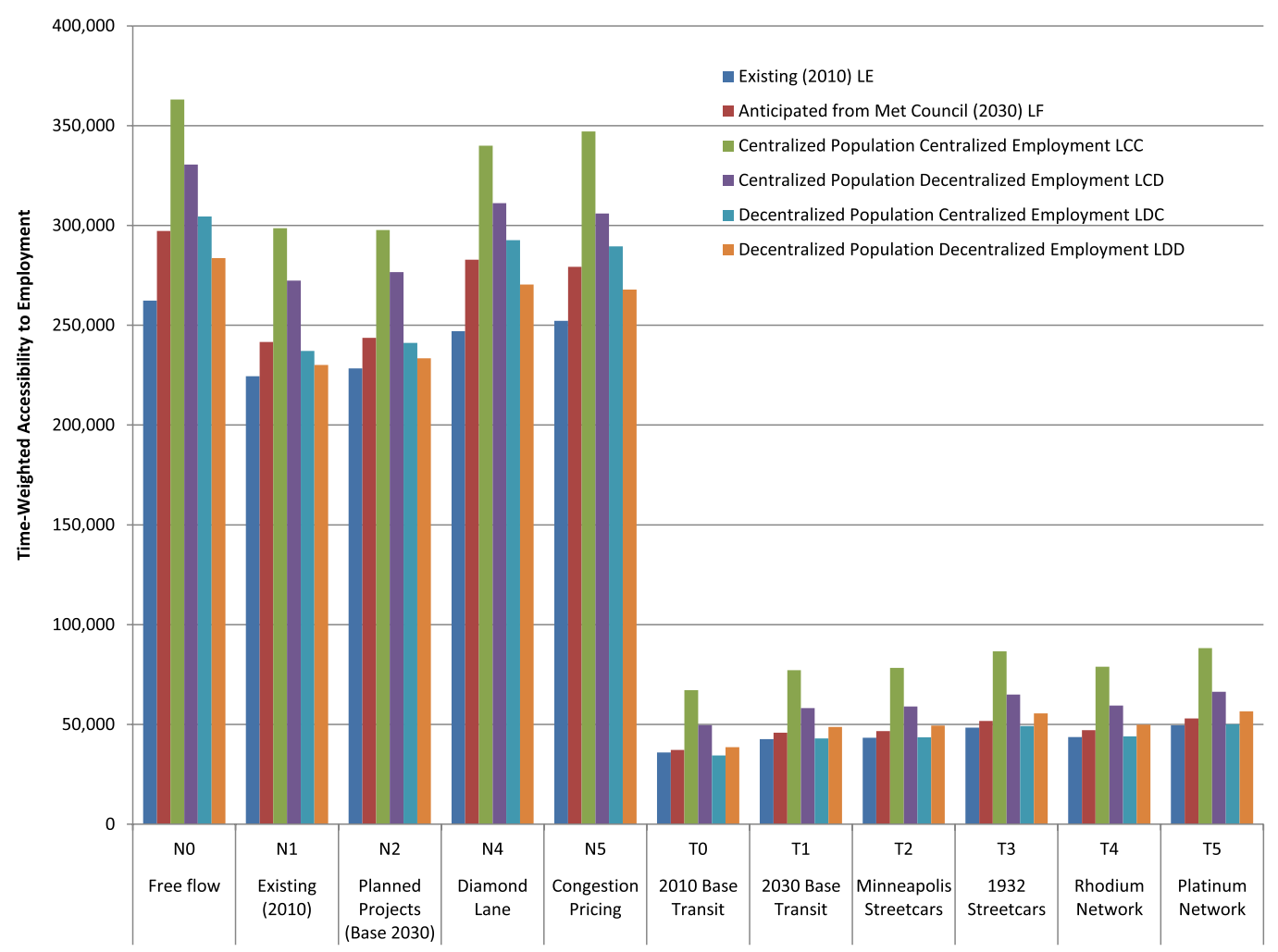

Figure 10 Time-weighted accessibility to jobs

similar. Remember while the trip generation is the same across networks, the trip distribution is not, and depends on congestion levels. So adding to capacity in some areas will re-distribute demand and reroute traffic and thus shift congestion. While there may be a net reduction in congestion (this is not guaranteed), the change in congestion will make some places more accessible and others less accessible. The model nets this out and solves for the equilibrium. It turns out adding capacity in some places reduces accessibility to others. The added capacity in general adds about $2 \%$ to 20 minute accessibility to jobs and $1 \%$ to 30 minute regional accessibility to jobs.

The congestion pricing scenario is similar to the Diamond Lane network, as personweighed accessibility falls within $+/-3 \%$ for all land uses. Congestion pricing is more effective than diamond lanes for 2010 and centralized land uses. This model accounts for the spatial benefits of tolling in terms of reallocating traffic to better routes, and some redistribution of traffic to different destinations, but does not fully account for time of day shifts, as the trip generation (by time of day) is fixed.

Transit accessibility shows relatively little variation between the different scenarios on a network level (however there are significant local improvements associated with these scenarios).

Figures 11 shows the ratio of highway to transit accessibility by zone at 20 minutes. The highway network, transit network, and land use in these figures are all from the Metropolitan Council's 2030 Comprehensive Plan. At 20 minutes, there are some zones with a ratio near 1, 


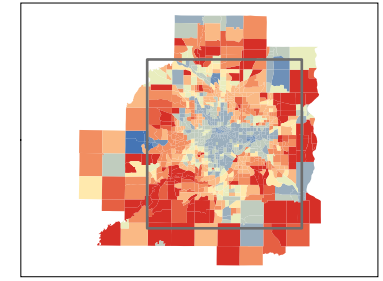

2030 Highway Network 2030 Base Transit Network with $2030 \mathrm{LU}$ forecasts

Ratio of Highway Accessibility to Transit Accessibility 20 Minutes

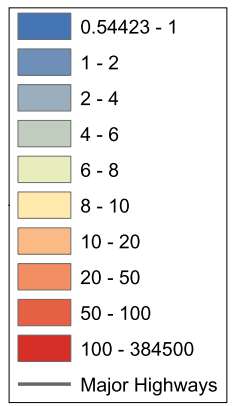

Zone Structure Displayed: Traffic Analysis Zone Boundaries Primary Data Sources: MnDOT, Twin Cities Metropolitan Counci,

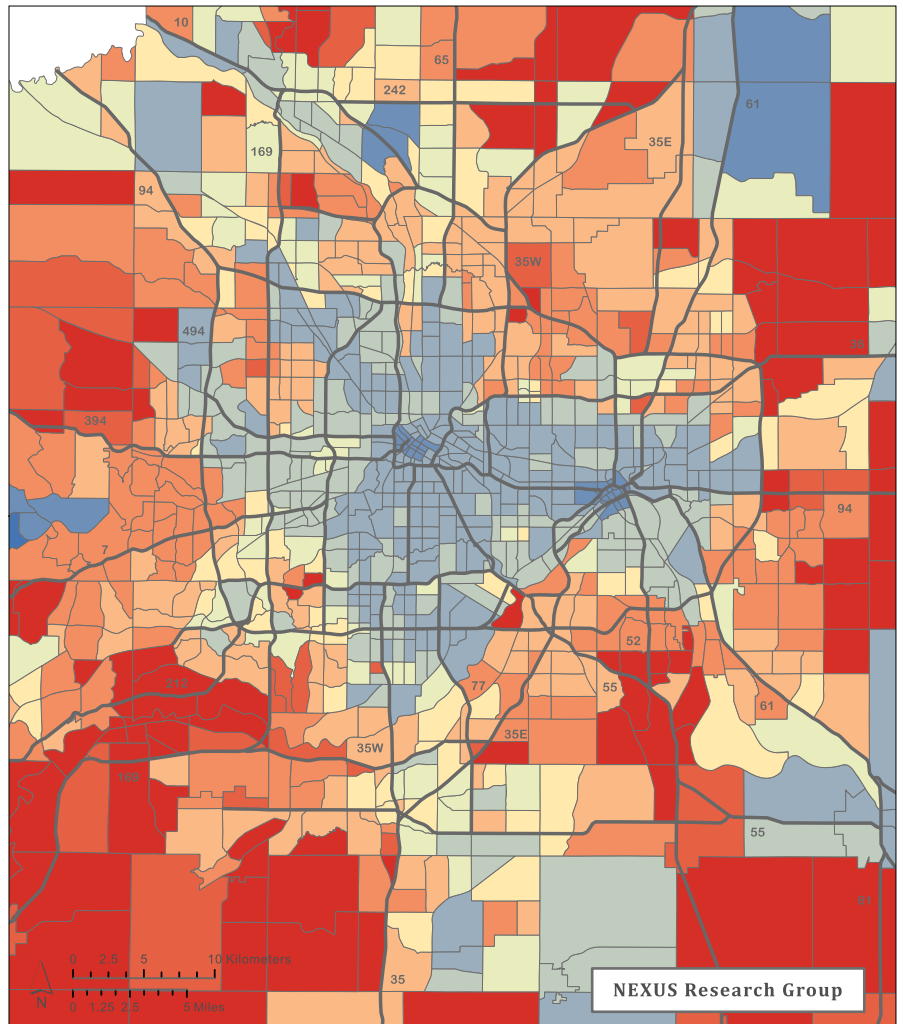

Figure 11 Ratio of highway to transit accessibility: 20 minutes

while many outlying areas have ratios well over 100 . Transit fares relatively well in this comparison in Minneapolis, Saint Paul, and some of the inner-ring suburbs, but does poorly outside of the I-494/694 Beltway. The highest ratios are found in outer-ring suburbs and exurban areas, which is to be expected.

\section{Conclusions}

This study uses accessibility measures to compare a set of planning scenarios for the Twin Cities Metropolitan Area. The fact that centralized population and employment produces the highest accessibility regardless of the network chosen should not be surprising. It is conventional wisdom that concentrating opportunities in one place, in this case the center of the metropolitan area, will lead to higher accessibility. The order of the other scenarios has some interesting implications for planning, though.

First, a change in land use is more effective than the anticipated changes in the network. For both highway and transit accessibility, the best land use scenario on the worst network can outperform at least two land use scenarios on the best network. Moving to a freeflow network (through technological change or through pricing) would have significant time accessibility improvements $(20 \%)$ although clearly at a high monetary cost. Levinson and Marion (2010) came to the conclusion that network changes have a more local effect while land use changes have a regional effect. That is confirmed here. 
Most American cities initially developed with employment concentrated in the central business district and population dispersed more evenly across the region. Minneapolis and Saint Paul are no exception, and the highway and transit networks are built to serve the trip distribution from this development pattern. The employment distribution has become much more polycentric over the last 50 years, so it makes sense that the land use scenario that moves back toward the pattern the networks were designed for is effective. On the other hand, the exact opposite scenario (centralized population, decentralized employment) has higher accessibility, despite the bias for centralized employment in the network design. This suggests that in a city with a different network structure, the $L_{C D}$ scenario might have even higher accessibility, perhaps something similar to the all centralized scenario.

The results of this study show that accessibility measures are a viable tool for comparing planning scenarios. With a selection of possible scenarios as broad as this one, it would be difficult to select one as the best choice to implement without knowing more about the cost and feasibility of each option. With that disclaimer, we can recommend the $L_{C D}$ and congestion pricing scenarios for further study as these perform very well and we expect that they would have a lower implementation cost than the alternatives. As for transit, no option stands out on a network level, so we suggest that the decision to implement these be made on a corridor level. If the trend of decentralized development is too difficult to reverse, an investment in congestion pricing or HOT lanes might be best. Handy (1996) suggests a combination of land use policy and road pricing because land use policy only affects growth and it can take many years for a change in policy to have a significant impact on travel behavior (although the 20 year time frame of our study is enough to see that impact). Cervero (2003) argues that road expansion can be good policy when it is complemented by land use planning and pricing initiatives. On the other hand, decentralized development renders the transit system ineffective and reduces the effectiveness of the highway system in connecting people to jobs. A concentrated effort for higher densities and infill development in the central cities would benefit accessibility the most, and this study shows that increasing the centralization of population is more important than centralizing additional employment. A good use for this type of analysis would be to prioritize investments and land use strategies based on how "accessibility-effective" they are, or how much accessibility per unit dollar of investment. In determining final investment and planning strategies, the value of accessibility to jobs or labor needs to be traded off against other values.

\section{References}

Anderson D and Mohring H 1997 Congestion costs and congestion pricing. In Greene D L, Jones D W, and Delucchi M A (eds) The Full Costs and Benefits of Transportation: Contributions to Theory, Method and Measurement. Berlin, Springer: 315-36

Bartholomew K and Ewing R 2009 Land use-transportation scenarios and future vehicle travel and land consumption. Journal of the American Planning Association 75: 13-27

Bertolini L, Le Clercq F, and Kapoen L 2005 Sustainable accessibility: A conceptual framework to integrate transport and land use plan-making, Two test-applications in the Netherlands and a reflection on the way forward. Transport Policy 12: 207-20

Boarnet M and Chalermpong S 2001 New highways, house prices, and urban development: A case study of toll roads in Orange County, CA. Housing Policy Debate 12: 575-605

Caliper 2008 TransCAD 5.0 User's Guide. Newton, MA, Caliper Corporation

Cervero R 2003 Road expansion, urban growth, and induced travel: A path analysis. Journal of the American Planning Association 69: 145-63

Daganzo C and Sheffi Y 1977 On stochastic models of traffic assignment. Transportation Science 11: 253

Dial R 1971 A probabilistic multipath traffic assignment model which obviates path enumeration. Transportation Research 5: 83-111 
Esri 2009 ArcGIS (Version 9.3.1). Redlands, CA, Esri

Geurs K and Van Wee B 2004 Accessibility evaluation of land-use and transport strategies: Review and research directions. Journal of Transport Geography 12: 127-40

Guo D and Wang H 2011 Automatic region building for spatial analysis. Transactions in GIS 15: 29-45

Hägerstrand T 1970 What about people in regional science? Papers in Regional Science 24: 6-21

Handy S 1996 Methodologies for exploring the link between urban form and travel behavior. Transportation Research Part D: Transport and Environment 1: 151-65

Hansen W G 1959 How accessibility shapes land use. Journal of the American Institute of Planners 25(2): 73-6

Harvey J 1991 Modelling accessibility using space-time prism concepts within geographical information systems. International Journal of Geographical Information Systems 5: 287-301

Krizek K, El-Geneidy A M, Iacono M, and Horning J 2007 Access to Destinations: Refining Methods for Calculating Non-auto Travel Times. St. Paul, MN, Minnesota Department of Transportation Technical Report No. 24

Kwan M-P 1998 Space-time and integral measures of individual accessibility: A comparative analysis using a point-based framework. Geographical Analysis 30: 191-216

Lenntorp B 1978 A time-geographic simulation model of individual activity programmes. Timing Space and Spacing Time 2: 162-80

Lenntorp B and Hort P 1976 Paths in Space-time Environments: A Time-geographic Study of Movement Possibilities of Individuals. Lund, Sweden, Department of Geography, Royal University of Lund

Leurent F 1997 Curbing the computational difficulty of the logit equilibrium assignment model. Transportation Research Part B: Methodological 31: 315-26

Levinson D 1998 Accessibility and the journey to work. Journal of Transport Geography 6: 11-21

Levinson D 2010 Equity effects of road pricing: A review. Transport Reviews 30: 33-57

Levinson D and Marion B 2010 The City is Flatter: Changing Patterns of Job and Labor Access in MinneapolisSaint Paul, 1995-2005. Unpublished Technical Report

Levinson D M and Kumar A 1994 A multi-modal trip distribution model. Transportation Research Record 1466: 124-31

Miller H 1999 Measuring space-time accessibility benefits within transportation networks: Basic theory and computational procedures. Geographical Analysis 31: 1-26

Ni D, Leonard J, Guin A, and Williams B 2004 Systematic approach for validating traffic simulation models. Transportation Research Record 1876: 20-31

O'Sullivan D, Morrison A, and Shearer J 2000 Using desktop GIS for the investigation of accessibility by public transport: An isochrone approach. International Journal of Geographical Information Science 14: 85-104

Parthasarathi P 2011 Network Structure and Travel. Unpublished Ph.D. Dissertation, University of Minnesota

Raubal M, Miller H, and Bridwell S 2004 User-centred time geography for location-based services. Geografiska Annaler: Series B, Human Geography 86: 245-65

Safirova E, Gillingham K, and Houde S 2007 Measuring marginal congestion costs of urban transportation: Do networks matter? Transportation Research Part A: Policy and Practice 41: 734-49

Swisher M, Eisele W, Ungemah D, and Goodin G 2002 Life-cycle graphical representation of managed HOV lane evolution. In Proceedings of the Eleventh International HOV Conference, Seattle, Washington

Walton W and Shaw J 2003 Applying the new appraisal approach to transport policy at the local level in the UK. Journal of Transport Geography 11: 1-12

Wegmann F and Everett J 2008 Minimum Travel Demand Model Calibration and Validation Guidelines for the State of Tennessee. Knoxville, University of Tennessee, Center for Transportation Research Research Report

Zhang L 2011 Behavioral foundation of route choice and traffic assignment. Transportation Research Record 2254: 1-10

Zhang L, Levinson D, and Zhu S 2008 Agent-based model of price competition, capacity choice, and product differentiation on congested networks. Journal of Transport Economics and Policy 42: 435-61 